Research Article

\title{
Dynamic Analysis of the High-Speed and Long-Runout Landslide Movement Process Based on the Discrete Element Method: A Case Study of the Shuicheng Landslide in Guizhou, China
}

\author{
Guoqing Xia $\mathbb{D}^{\mathbb{1}},{ }^{1}$ Chun Liu $\mathbb{D}^{\mathbb{D}},{ }^{1}$ Chong $X \mathrm{u}^{2}$ and Tiancheng Le ${ }^{1}$ \\ ${ }^{1}$ School of Earth Sciences and Engineering, Nanjing University, Nanjing 210023, China \\ ${ }^{2}$ National Institute of Natural Hazards, \\ Ministry of Emergency Management of China (former Institute of Crustal Dynamics, China Earthquake Administration), \\ Beijing 100085, China \\ Correspondence should be addressed to Chun Liu; chunliu@nju.edu.cn
}

Received 23 September 2020; Revised 14 December 2020; Accepted 18 February 2021; Published 28 February 2021

Academic Editor: Loke Foong

Copyright (C) 2021 Guoqing Xia et al. This is an open access article distributed under the Creative Commons Attribution License, which permits unrestricted use, distribution, and reproduction in any medium, provided the original work is properly cited.

\begin{abstract}
On July 23, 2019, a high-speed and long-runout landslide occurred in Jichang Town, Shuicheng County, Guizhou Province, China, causing 42 deaths and 9 missing. This paper used the discrete element software MatDEM to construct a three-dimensional discrete element model based on digital elevation data and then simulated and analyzed the movement and accumulation process of the landslide. The maximum average velocity of the source area elements reached $14 \mathrm{~m} / \mathrm{s}$ when passed through the scraping area; meanwhile, the velocity of the scraping area elements increased rapidly. At $90 \mathrm{~s}$, the maximum displacement of the source area elements reached $1358.5 \mathrm{~m}$. The heat generated during the movement of the landslide was mainly the frictional heat, and the frictional heat increased sharply when the source area elements passed through the scraping area. The change of frictional heat has a certain positive correlation with the velocity of the scraping area elements. Finally, the volume of the scraping area elements was 2.4 times greater than the source area elements in the deposits. The scraping effect increases the volume of the sliding body and expands the impact area of the landslide disaster. Additionally, by setting different compressive and tensile strengths as well as internal friction coefficients to analyze the influences of their value changes on the landslide movement process, the results show that the smaller the strengths and internal friction coefficient of the model, the greater the depth and area of the scraping area, which will result in a thicker accumulation; meanwhile, the average displacement, average velocity, and heat will also increase.
\end{abstract}

\section{Introduction}

High-speed and long-runout landslide is a landslide with great velocity and displacement, which has the characteristics of huge volume, strong destructiveness, and high fluidity [1-3]. China has a vast territory and complex geological structure, with a wide range of landslide hazards [4], especially in southwest mountainous areas [5], such as the Touzhai landslide [6], Yigong landslide [7], Donghekou landslide [8], Jiweishan landslide [9], Guanling landslide [10], and Xinmo landslide [11]. The high-speed and longrunout landslide often causes huge property losses and casualties due to the difficulty of early identification and spatial prediction. Research on the genetic mechanism and movement characteristics of high-speed and long-runout landslides has important practical significance for preventing landslide disasters.

High-speed and long-runout landslides last for a short time and generally occur in remote areas, so it is difficult to obtain information about the real situation when the landslide occurs. Therefore, many researchers have conducted model tests to study the genetic mechanism and characteristics of high-speed and long-runout landslides [12-15]. A model test can reproduce the movement and accumulation process of the landslide, but due to the scale effect of the high-speed and long-runout landslide [1], the reliability of the model test results still remains to be proved. 
Numerical simulations have played an important role in quantitatively analyzing landslide movement and evaluating the area of landslide disasters owing to their low cost, high efficiency, and avoidance of scale limitation in the test. At present, many numerical simulation methods have been applied to the study of the mechanism and failure process of landslides. Xu et al. used the dynamic finite element method (FEM) to reconstruct the 3D failure and associated damming caused by the Tangjiashan landslide [16]. There are many unknown parameters to be solved in the finite element method, which requires a large scale of equations for the solution and a large amount of data for calculation. The finite difference method (FDM) can be used to simulate landslides and the process of flow slide and soil creep $[9,17,18]$. Its disadvantage is the difficulty in guaranteeing the conservation characteristics of discrete equations. Li et al. presented a methodology based on the smoothed particle hydrodynamics (SPH) approach, which can simultaneously determine multiple failure slip surfaces and the debris flow process. But, it is time consuming to carry out an $\mathrm{SPH}$ analysis, and the postprocessing of the results in a $\mathrm{SPH}$ analysis requires a certain amount of effort [19]. Song et al. used the discontinuous deformation analysis (DDA) to simulate the run-out and deposit pattern of the Daguangbao landslide [20]. The discrete element method (DEM) can be used to investigate the failure processes and mechanisms of jointed rock slopes as well as fragmentation during rockfalls and rock avalanches [21, 22]. The discrete element method can be computationally expensive when the number of elements is very great. There are also some coupling methods. Zhou et al. presented a numerical method combined with a FEM and DEM for simulation of the landslide debris flow under seismic loading [23], while the mechanical parameters are hard to determine. Cascini et al. used an enhanced numerical model which combines a 3D depth-integrated hydro-mechanical coupled SPH model for the propagation analysis of debris flows and a 1D vertical FDM model for the evaluation of the pore water pressure [24].

During the movement of a landslide, the sliding bed can be scraped to increase the volume of the sliding body [25-28], thereby expanding the area of the disaster. The analysis of the parameters affecting the scraping effect is of great significance for evaluating disaster risk. Some studies have analyzed the influence of friction angle, pore water pressure, consolidation coefficient, friction coefficient, and stiffness coefficient on the scraping effect [29-32]. Zhang et al. [33] used PFC to simulate the motion process of the Jiweishan landslide and obtained the conclusion that the friction coefficient of the sliding surface and strength of the sliding mass significantly affect the distribution of the sliding mass in deposited areas.

Since the real movement process of a high-speed and long-runout landslide is difficult to obtain, this paper used the discrete element software MatDEM to rebuild the movement process of the Shuicheng landslide. Firstly, we used MatDEM to construct a three-dimensional discrete element model based on digital elevation data and simulated the initiation, high-speed sliding, and accumulation process of the Shuicheng landslide. Subsequently, the displacement, velocity, heat generated during the movement of the landslide, and the distribution characteristics of deposits were analyzed. Finally, by setting different compressive strengths, tensile strengths, and friction coefficients, we analyzed the influence of those parameters' value change on the landslide movement process. MatDEM uses the matrix method to perform iterative calculations on the GPU, which is better than other similar discrete element software in terms of calculation quantity and time [34]. Using MatDEM, people can quickly evaluate landslide hazards, determine the scope of potential hazards, and provide guidance for disaster relief.

\section{Study Area}

2.1. Overview of the Landslide. At around $20: 40$ on July 23, 2019, a high-speed and long-runout landslide occurred in Pingdi Village, Jichang Town, Shuicheng County, Guizhou Province, China $\left(26^{\circ} 15^{\prime} 35^{\prime \prime} \mathrm{N}, 104^{\circ} 40^{\prime} 24^{\prime \prime} \mathrm{E}\right.$ ) (Figure 1). The total length of the sliding body was more than $1.3 \mathrm{~km}$. The elevations of the scrap and the toe of the landslide were about $1740 \mathrm{~m}$ and $1230 \mathrm{~m}$, respectively, and the elevation difference is about $500 \mathrm{~m}$. The sliding direction was NNE. The total affected area of the landslide is about $3.3 \times 10^{5} \mathrm{~m}^{2}$, and the sliding body volume was about $2 \times 10^{6} \mathrm{~m}^{3}$ [35]. The landslide scene taken by the UAV (unmanned aerial vehicle) is shown in Figure 2. By comparing the photos before and after the sliding (Figure 3), the Shuicheng landslide can be divided into three areas: the source, scraping, and deposition areas.

2.2. Topography and Landform. Shuicheng County is located in the western part of Guizhou Province, China, in the middle of the Yunnan-Guizhou Plateau. The terrain is undulating, dominated by high-altitude mountains. The terrain slowly descends from northwest to southeast. The highest elevation is $2861 \mathrm{~m}$, the lowest elevation is $633 \mathrm{~m}$, and the average elevation is $1747 \mathrm{~m}$. The development of karst landforms in the study area provides basic conditions for the development of landslides, ground collapses, and other geological hazards. Landslides in the area mainly occur in the gradient between $20^{\circ}$ and $50^{\circ}$ [36].

High and steep terrain conditions are the key factors that trigger landslides [37]. The upper part of the Shuicheng landslide was steep with an average dip angle of $28^{\circ}$, while the lower part was slightly gentler with an average dip angle of $10^{\circ}$. There were multiple gentle slopes and terraces in the trailing edge and central area of the landslide, which conducted to the collection of rainwater [38]. In addition, the narrow gullies on both sides of the landslide formed a favorable circulation channel for the sliding body.

2.3. Geological Conditions. The study area is located in the middle of the Weining northwest trending structure deformation zone in the Liupanshui fault depression of the Yangtze platform [38]. The exposed strata mainly include the Carboniferous $(C)$, Permian $(P)$, and Triassic $(T)$. The stratigraphic lithologies are the Upper-Middle Devonian 


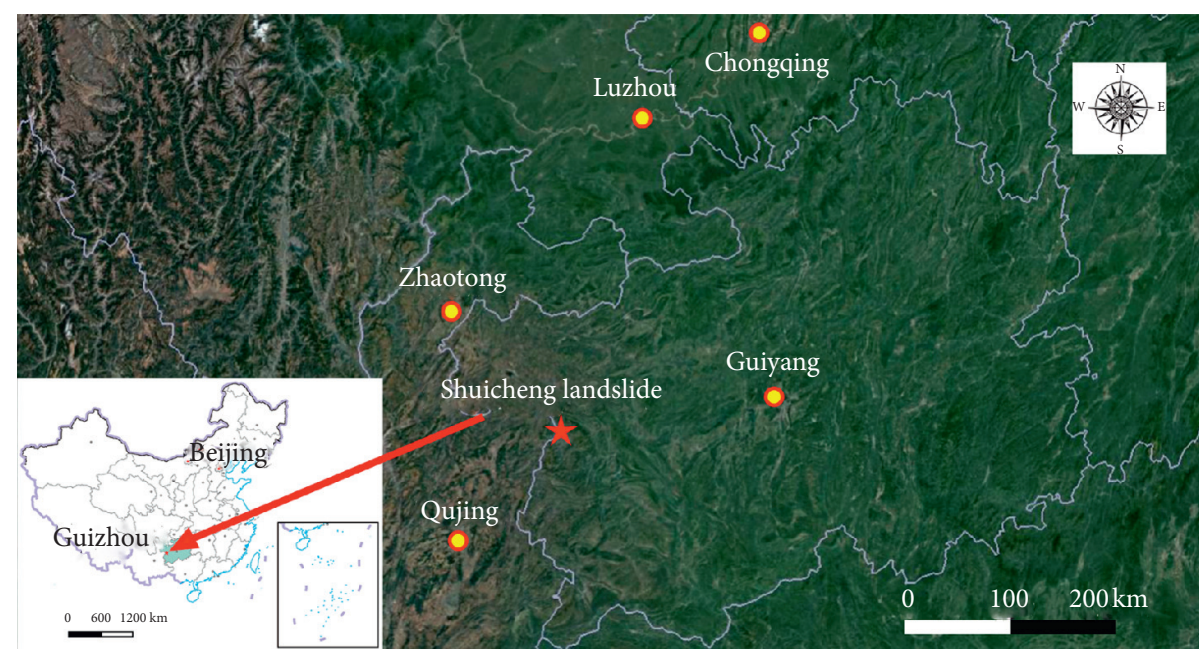

Figure 1: Geographical location of the Shuicheng landslide.

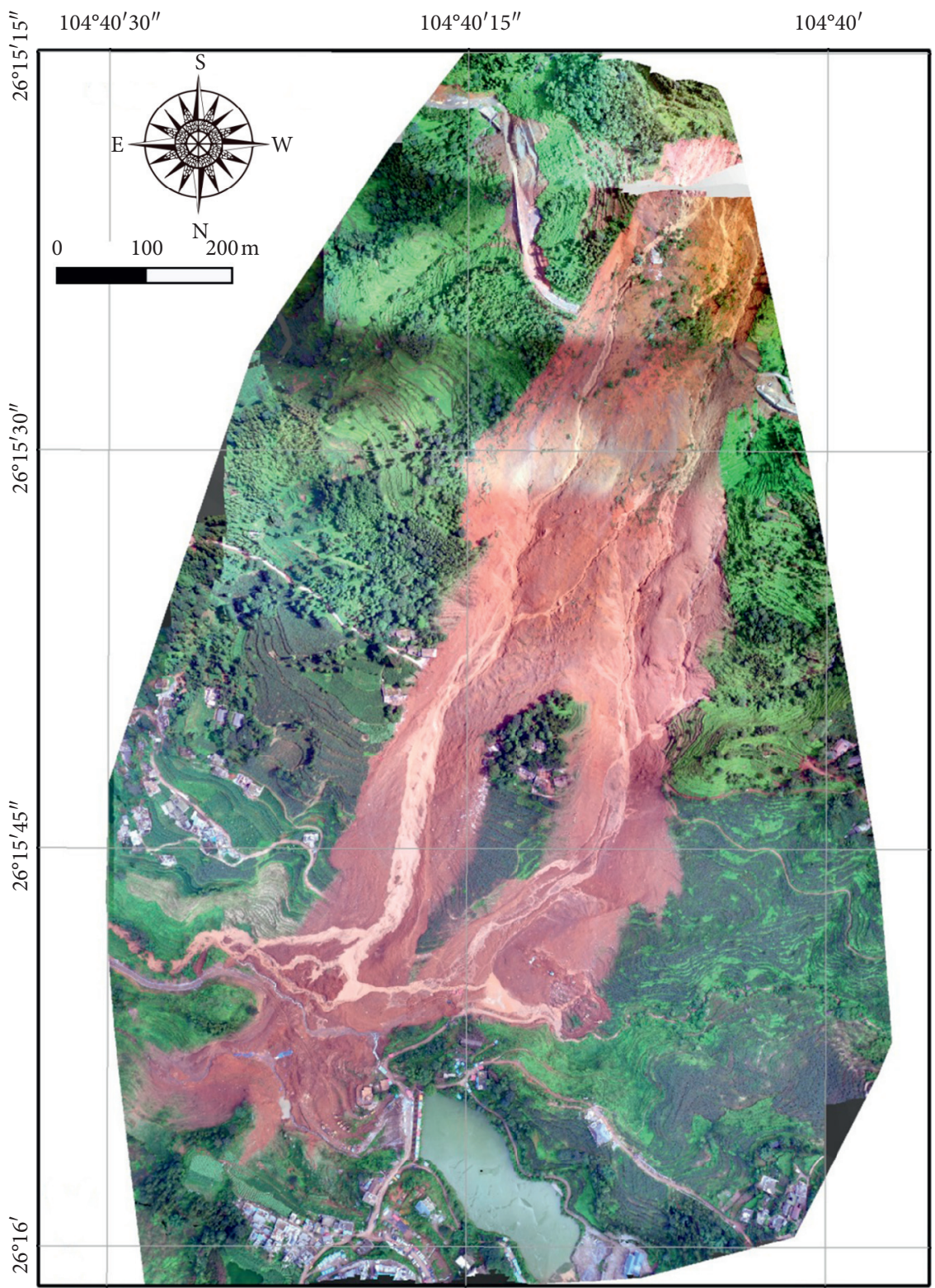

FIgURE 2: UAV photograph of the Shuicheng landslide. 


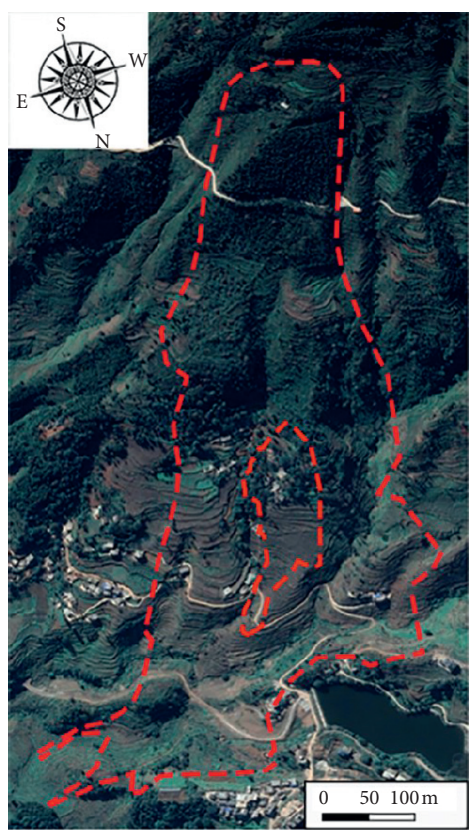

(a)

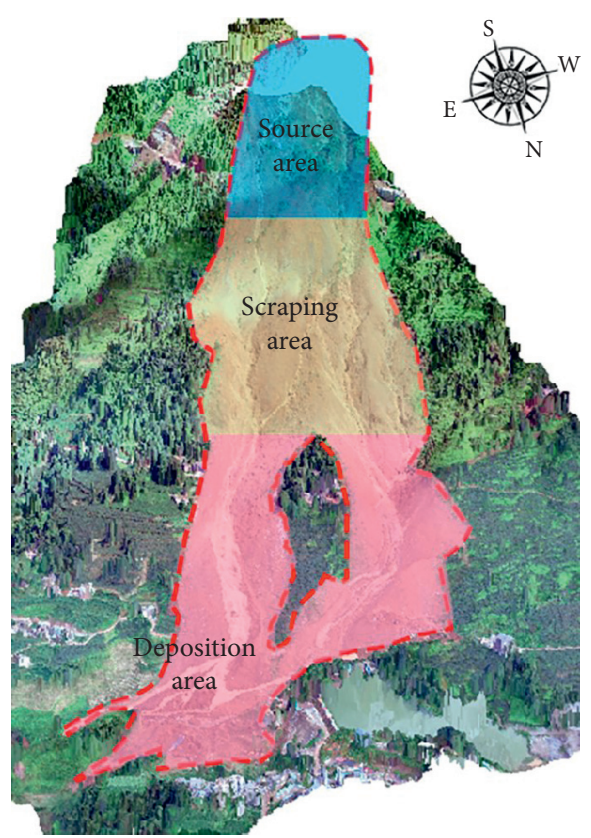

(b)

FIgURE 3: Comparison of (a) the presliding satellite photo from Google Earth and (b) the postsliding photo taken by the UAV of the Shuicheng landslide.

gray crystalline dolomite $\left(D_{2-3}\right)$, the Lower Carboniferous limestone $\left(C_{1}\right)$, the Upper Carboniferous dolomite $\left(C_{2}, C_{3}\right)$, the Lower Permian quartz, sandstone, and limestone $\left(P_{1}\right)$, the Middle Permian Emeishan basalt $\left(P_{2}\right)$, and the Lower Triassic limestone, sandstone, and claystone $\left(T_{1}\right)$ [35]. The Shuicheng landslide occurred in the Emeishan basalt in the Middle Permian. Due to the columnar joints in the basalt of the Shuicheng landslide and the influence of weathering and tectonic effects, the basalt is relatively broken, and unstable structural surfaces develop inside it, which is easy to cause geological disasters [39]. The joints and fractures in basalt are also natural seepage channels [40].

2.4. Climate and Rainfall Characteristics. Shuicheng County has obvious characteristics of plateau monsoon climate, with abundant rainfall and annual precipitation ranging from 940 to $1450 \mathrm{~mm}$ [36]. The effective rainfall in the early stage has a great inducing effect on the occurrence of landslides [41, 42]. There were 3 heavy rains in the week before the landslide on July 23, which were $49 \mathrm{~mm}$ (July 19), $37.1 \mathrm{~mm}$ (July 20), and $85.5 \mathrm{~mm}$ (July 22), respectively. The three days of rainfall were the three most rainy days in July, even the rainfall was close to the magnitude of the heavy rainstorm on July 22 . Rainstorms often cause the phreatic line to rise which in turn induces seepage damage [43], and the concentrated mountains and rainfall are the causes of landslides [44]. The accumulated rainfall from July 18 to July 22 was $189 \mathrm{~mm}$ (Figure 4) [39]. Continuous rainfall will increase the pore water pressure inside the rock and soil of the slope, reducing the effective stress. Soaking in the rain water will also reduce the shear strength of the rock and soil and increase the self-weight stress of the slope body. Hu et al. [45] carried out ring shear tests on dry and saturated mudstone granules with different grain sizes, and the results showed that saturated gravel-sized granules exhibited significant and abrupt reversible rateweakening. In addition, the rain will lubricate the potential sliding surface. Eventually, the sliding force continues to increase until it becomes greater than the antisliding force, which will cause landslide disasters to happen.

\section{Numerical Model of the Shuicheng Landslide}

3.1. The Discrete Element Method. In order to quantitatively analyze the movement process of the Shuicheng landslide due to instability and failure, this paper used the discrete element software MatDEM to simulate the landslide. MatDEM is based on the innovative matrix discrete element calculation method, which realizes the fast simulation of the large-scale discrete element model with millions of elements $[46,47]$. The discrete element method was proposed by Cundall and Strack [48], which builds a rock and soil model by packing a series of discrete elements. The elements are connected and interacted through a certain contact, and numerical simulation is carried out through the time-step iteration based on Newton's law of motion.

In this paper, the linear elastic contact model is used. As shown in Figure 5, the force between elements is composed of normal and shear forces, which can be determined by

$$
\begin{aligned}
& F_{n}=K_{n} X_{n}, \\
& F_{s}=K_{s} X_{s},
\end{aligned}
$$

where $F_{n}$ is the normal force, $K_{n}$ is the normal stiffness, $X_{n}$ is the normal relative displacement, $F_{s}$ is the shear force, $K_{s}$ is 




FIGURE 4: Rainfall preceding the Shuncheng landslide.

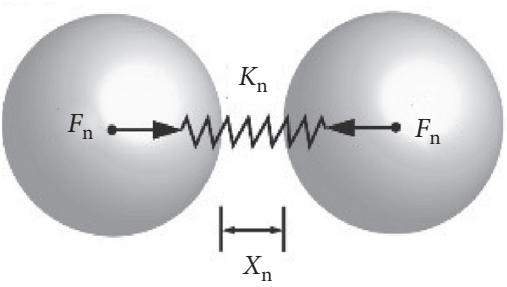

(a)

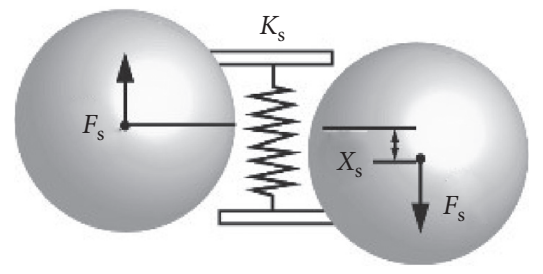

(b)

FIgURE 5: Linear elastic contact model. (a) Normal force between elements. (b) Shear force between elements.

the shear stiffness, and $X_{s}$ is the tangential relative displacement. The maximum normal force $\left(F_{n \max }\right)$ that the cementation between elements can withstand is

$$
F_{n \max }=K_{n} X_{b},
$$

where $X_{b}$ is the breaking displacement. When the relative displacement between the two elements is greater than $X_{b}$, the cementation between the elements will break, and there is no longer any force. The maximum allowable shear force $\left(F_{\text {smax }}\right)$ for cementation between elements is

$$
F_{s \max }=F_{s 0}-\mu_{p} F_{n},
$$

where $F_{s 0}$ is the initial shear resistance between the elements and $\mu_{p}$ is the friction coefficient. When the shear force of the elements in the tangential direction is greater than $F_{\text {smax }}$, the cementation between the elements will break and relative sliding occurs, and the friction between the elements will reduce to $-\mu_{p} F_{n}$.

On the basis of knowing the resultant force of each particle, the displacement of elements is calculated by the iterative algorithm of time step. The resultant force is divided by the mass of the element to get the acceleration of the element at this moment. In the time step dT, the velocity of the next time step can be obtained by adding the velocity increment (acceleration times' time) to the current velocity, and the corresponding element displacement can be calculated by the average velocity in the time step. Then, the dynamic simulation of the discrete element method is realized by the iterative method until equilibrium or a specified number of iterations are reached.

3.2. Discrete Element Model of the Shuicheng Landslide. Firstly, we obtained high-resolution postsliding digital elevation data with a resolution of $0.1 \mathrm{~m}$ through UAV photography, and high-speed 3D dynamic shape measurement is essential and can be widely applied in application fields such as fluid dynamics, solid mechanics, and deformation analysis under stress, impact, and tension [49]. Secondly, according to the field investigation of the landslide area and the ALOS PALSAR data before sliding (resolution is $12.5 \mathrm{~m}$ ), the presliding digital elevation data was obtained through calculation [35]. Then, according to the scope of the landslide area, we built a cuboid model with the element radius of $1.55 \sim 2.23 \mathrm{~m}$, and the size of the model is $1400 \mathrm{~m} \times 600 \mathrm{~m} \times 714 \mathrm{~m}$. Finally, we used the landslide layers obtained by the digital elevation data to cut the cuboid model and generate a thin shell model of the landslide. The upper surface of the thin shell model is defined by the digital elevation data before the landslide sliding, and we moved the smaller value of the digital elevation data of the slope before 
and after the landslide down by $38.5 \mathrm{~m}$ to obtain the bottom surface. The discrete element model is shown in Figure 6(a). The color of an element in the figure represents its radius.

This paper inverts the macromechanical parameters of rock and soil based on the shape and distribution of the actual deposits of the landslide. Combining the previous experience of simulations of the landslide movement process using MatDEM [46, 47], the parameters are initially determined, and then, the parameters are continuously adjusted to make the numerical simulation results close to the actual situation. In MatDEM, the conversion formula proposed by Liu et al. (see Appendix for details) is used to convert the macromechanical parameters into the micromechanical ones required in the numerical simulation [50]. The macro- and micromechanical parameters of the material used in the numerical model of the Shuicheng landslide are shown in Table 1.

A fracture surface is established at the location inside the source area in Figure 3(b) to simulate the joint surface in basalt, and the element connections at the corresponding position in the model are completely broken to establish the initial fracture surface.

As shown in Figure 6(b), in order to further analyze the characteristics of the sliding body in the movement process, the active elements at the coordinate $X=320 \sim 700 \mathrm{~m}$ were set as the scraping area elements. The elements outside the landslide disaster area were set as the wall elements to reduce the amount of calculation. After the initial model of the landslide was established, gravity loads were applied to all elements, and the simulation of the landslide was completed through continuous iterative calculations. The total number of elements in the landslide model is 825,500, including 261,700 active elements. The numerical simulation carried out 432,500 time steps, which corresponds to 155.7 seconds in reality. By using a GPU workstation (Tesla P100 GPU) for calculation, this simulation costs about 18 hours.

\section{Simulation Results}

4.1. Characteristics of Displacement. In order to understand the regulation of movement of the Shuicheng landslide, the displacement of the landslide was first analyzed. Figures 7(a)$7(d)$ show the displacement of the landslide at $19 \mathrm{~s}, 44 \mathrm{~s}, 90 \mathrm{~s}$, and $121 \mathrm{~s}$, respectively. The color in the figure represents the displacement of the elements from the initial position. At $19 \mathrm{~s}$, the main slope body passed through the scraping area. Due to the change of topography, the main slope body was divided into two parts and slid down along the gully. At $44 \mathrm{~s}$, the front of the slope body reached the toe of the slope and began to accumulate. At $90 \mathrm{~s}$, the main body of the landslide had already accumulated and was in a basically stable state, only partial sliding and adjustment occurred. The displacement of the landslide at $121 \mathrm{~s}$ and the $90 \mathrm{~s}$ did not change much, only a small number of elements in the scraping area jumped and slid down. The shape and distribution of the final accumulation obtained by numerical simulation are more consistent with the reality.

Figure 8 shows the curves of the maximum and average displacement of the source area and the scraping area elements during the movement. At $90 \mathrm{~s}$, the scraping area elements reached the maximum displacement of $1358.5 \mathrm{~m}$, which is consistent with the result that Gao et al. obtained of the maximum displacement of $1360 \mathrm{~m}$ of the Shuicheng landslide by the numerical simulation software DAN3D [51]. The average displacement changed little after $60 \mathrm{~s}$, indicating that the main sliding process of the landslide had been completed, and only a few elements were further adjusted to achieve equilibrium. This is in line with the conclusion that $\mathrm{Ma}$ et al. proposed that the landslide movement process lasts about $60 \mathrm{~s}$ [35]. As the topography of the end of the accumulation area increased, some elements slid down after being pushed up, so after $40 \mathrm{~s}$, in Figure 8 , the maximum displacement of the element dropped down.

4.2. Characteristics of Velocity. Figure 9 shows the velocity curve of the source area and scraping area elements in the Shuicheng landslide within $155.7 \mathrm{~s}$. The simulation data shows that, as the depth of the sliding body increases, the velocity of the sliding elements gradually decreases. The average velocity of the top $6.25 \%$ of all elements approximately reflects the average velocity of the sliding body surface elements. It can be drawn from the figure that the velocity of the source area elements increased rapidly at the initial state of the landslide. At $19 \mathrm{~s}$, it can be drawn from Figure 7(a) that the source area elements passed through the scraping area and produced huge shear and dynamic interactions on the slope elements, which broke the connections between the scraping area elements, and the element speed increased rapidly. The average velocity of the source area elements reached a maximum of about $14 \mathrm{~m} / \mathrm{s}$ at $25 \mathrm{~s}$, which is closer to the average velocity of $16.6 \mathrm{~m} / \mathrm{s}$ calculated by $\mathrm{Ma}$ et al. using the Scheidegger method [35]. The average velocity of the top $6.25 \%$ of the source area elements was up to $44 \mathrm{~m} / \mathrm{s}$. The scraping area elements reached the maximum speed at about $34 \mathrm{~s}$, and it had a hysteresis compared with the source area elements. This is because it takes a certain time for the scraping area elements to start moving under the scraping effect to reach the maximum velocity. After that, the velocity of all elements gradually decreased, and at $90 \mathrm{~s}$, the curve of average velocity of the elements gradually became flat. At $121 \mathrm{~s}$, the average velocity of all elements dropped to nearly 0 , indicating that the elements' motion at this moment was basically in a stable accumulation state, which is consistent with the phenomenon observed in Figure $7(d)$.

4.3. Characteristics of the Heat Transformation. Figure 10 shows the heat change curve during the sliding process of the landslide. The heat is mainly derived from the friction heat generated by the mutual friction between the elements. The change trends of the total heat and the friction heat are basically the same, and the total energy of nearly $8 \times 10^{12} \mathrm{~J}$ is finally generated. At about $19 \mathrm{~s}$, due to the source area elements passing through the scraping area and generating friction, the frictional heat increased rapidly. When the frictional force is greater than the maximum shear force that 




(a)

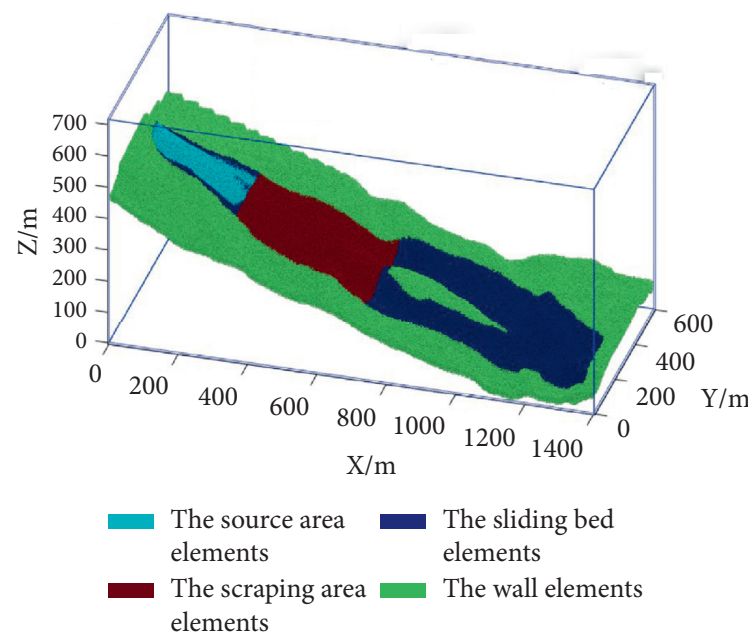

(b)

FIGURE 6: The discrete element model of the Shuicheng landslide. (a) Initial model. (b) Grouped model.

TABLE 1: Macro- and micromechanical parameters of the material in the Shuicheng landslide.

\begin{tabular}{lc}
\hline Macromechanical parameters & 29 \\
\hline Young's modulus $(\mathrm{GPa})$ & 0.1 \\
Poisson's ratio & 30 \\
Tensile strength $(\mathrm{MPa})$ & 300 \\
Compressive strength $(\mathrm{MPa})$ & 0.43 \\
Internal friction coefficient & 2600 \\
Density $\left(\mathrm{kg} / \mathrm{m}^{3}\right)$ & 44.86 \\
Normal stiffness $(\mathrm{GN} / \mathrm{m})$ & 20.39 \\
Shear stiffness $(\mathrm{GN} / \mathrm{m})$ & 0.0023 \\
Breaking displacement $\mathrm{m}$ & 55.58 \\
Shear resistance $\mathrm{kN}$ & 0.0654 \\
Friction coefficient & \\
\hline
\end{tabular}

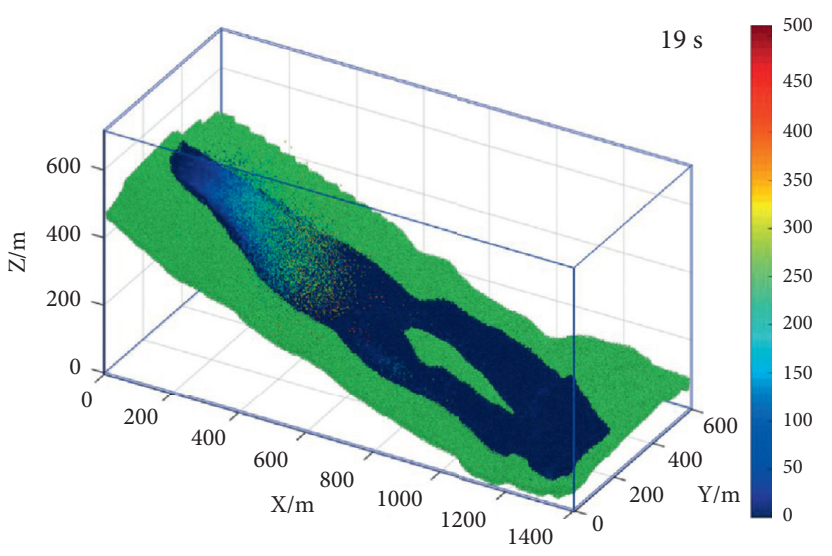

(a)

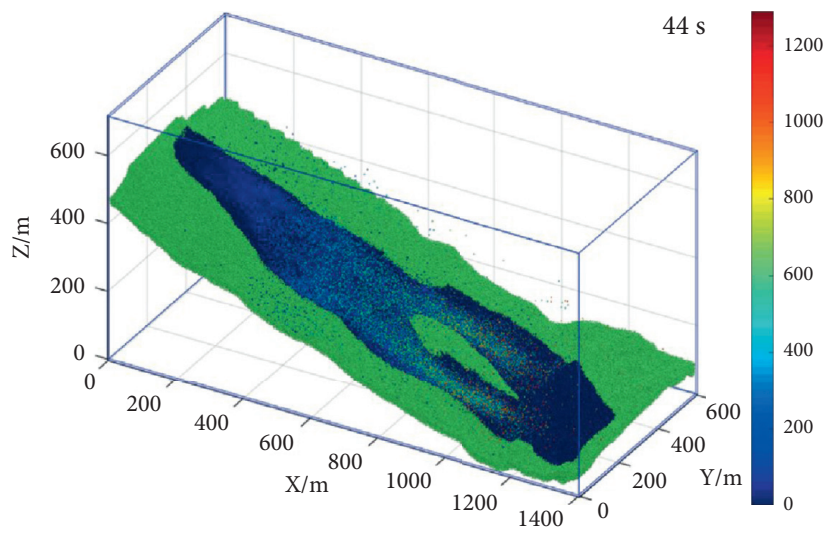

(b)

FIGURE 7: Continued. 


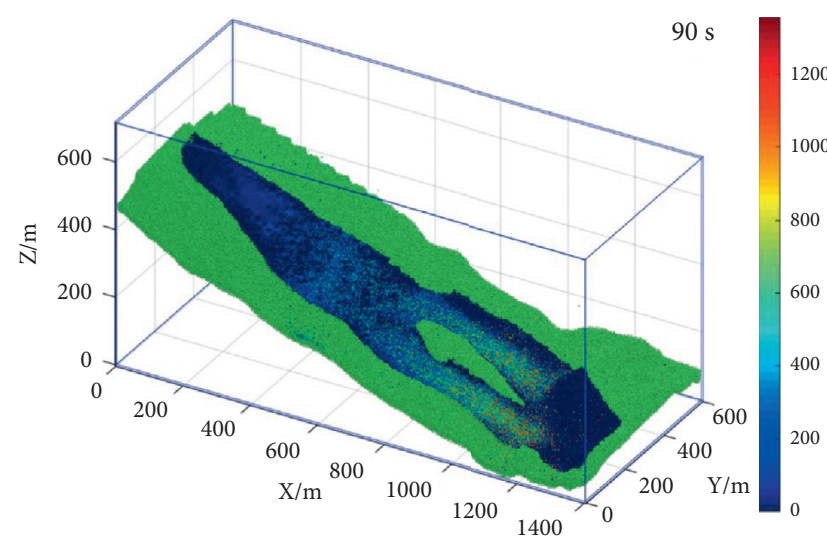

(c)

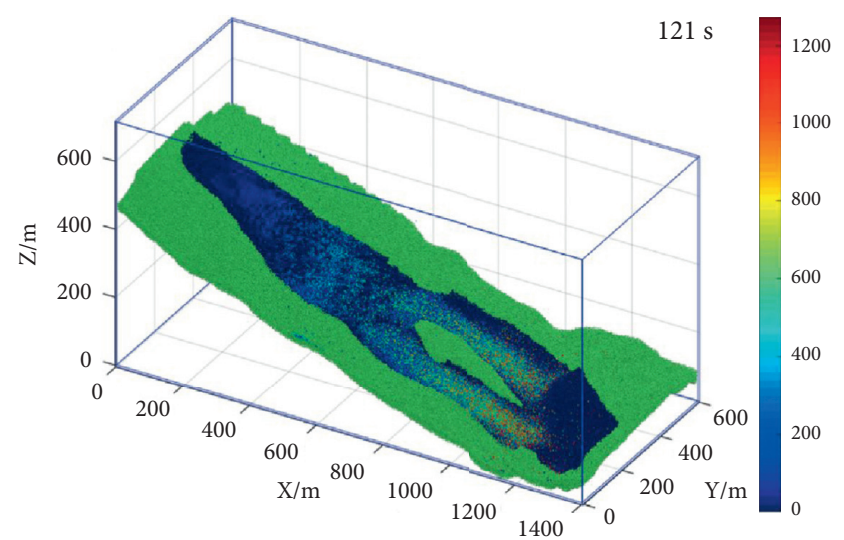

(d)

Figure 7: Change of displacement during the landslide movement. (a) 19 s. (b) 44 s. (c) 90 s. (d) 121 s.

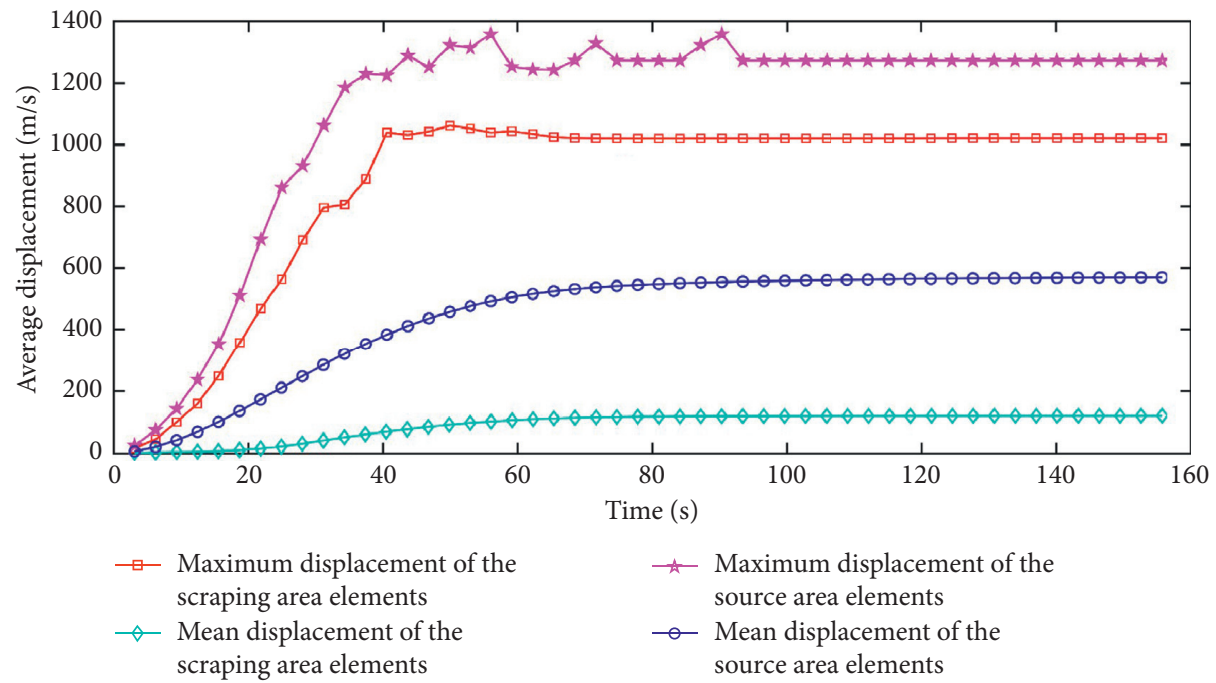

FIGURE 8: Curve of average displacement of the source area and the scraping area elements.

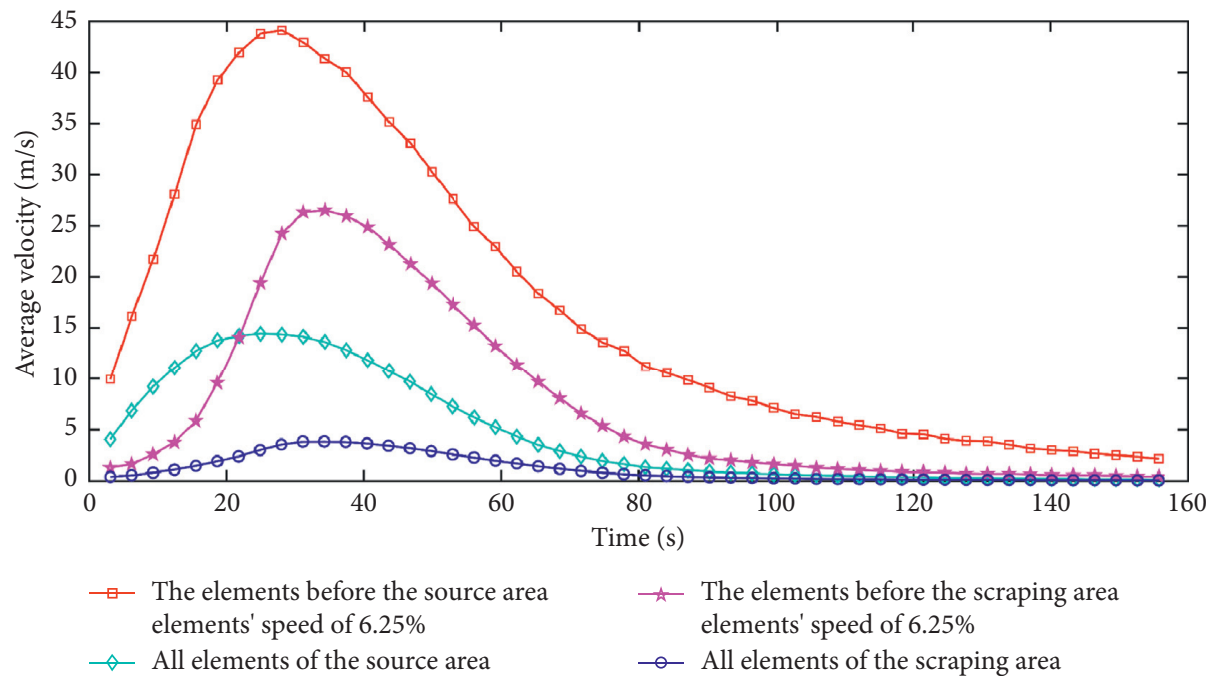

FIGURE 9: Curve of average velocity of the source area and the scraping area elements. 


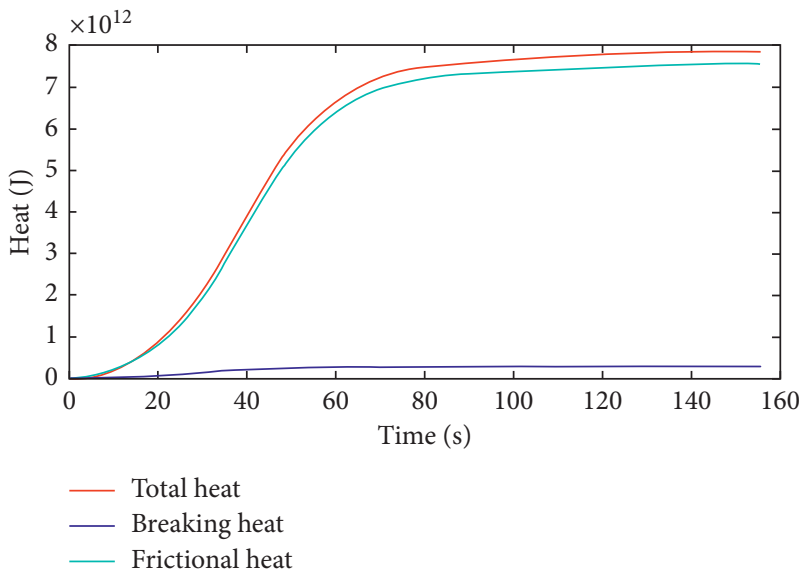

Figure 10: Heat change curve of the landslide movement.

an interelement connection can withstand, the connection will break, and the breaking heat will also begin to rise. Comparing Figures 9 and 10, it can be drawn that the heat has a certain positive correlation with the speed of the scraping area elements at $19 \mathrm{~s}$, and the average speed and heat of the scraping area elements both increase significantly. At 90 s, the main sliding body had stabilized, so the curve of the total heat generated during the movement of the landslide at this moment also gradually tended to be flat.

4.4. The Distribution Characteristics of the Deposit. In order to analyze the final accumulation and distribution characteristics of the elements, Figures 11(b)-11(d) plot the crosssectional views at $X=800,900$, and $1000 \mathrm{~m}$, respectively. It can be drawn that the source area and the scraping area elements are mixed together, and among them is the small mixed amount of other active elements. The deposits are mainly distributed in two gullies. Due to the scraping effect during the landslide movement, the volume of the sliding body increases. The final volume of the deposits is much larger than the volume of the source area elements. The volume of the scraping area elements is 2.4 times than the source area elements in the deposition area. Due to the scale effect of the high-speed and long-runout landslide, the increase in the volume of the landslide will make the slide distance farther and expand the impact area of the landslide disaster. Through comparison, it is found that the gully deposits on the left (west) are thicker than the one on the right (east), and the volume of the left deposits is larger, which is consistent with the actual situation [51].

\subsection{Influence of the Strengths and the Internal Friction Coefficient Change on the Landslide Movement Process}

4.5.1. Influence of the Compressive and Tensile Strengths' Change on the Landslide Movement Process. The basalt strength will reduce because of weathering. We used different compressive and tensile strengths to simulate the influence of strength drop of the landslide. Four sets of control experiments were carried out. The compressive strength was set to $150 \mathrm{MPa}$ (Material 1: $X_{\mathrm{b}}=1.3 \mathrm{~mm}$ and $\left.F_{\mathrm{s}_{0}}=1.80 \times 10^{9} \mathrm{~N}\right), 200 \mathrm{MPa}\left(\right.$ Material 2: $X_{\mathrm{b}}=1.7 \mathrm{~mm}$ and $\left.F_{s_{0}}=2.41 \times 10^{9} \mathrm{~N}\right), 250 \mathrm{MPa}\left(\right.$ Material 3: $X_{\mathrm{b}}=2.1 \mathrm{~mm}$ and $\left.F_{s_{0}}=3.01 \times 10^{9} \mathrm{~N}\right)$, and $300 \mathrm{MPa}\left(\right.$ Material $4: X_{\mathrm{b}}=2.6 \mathrm{~mm}$ and $\left.F \mathrm{~s}_{0}=3.61 \times 10^{9} \mathrm{~N}\right)$, respectively, and the tensile strength was set to one-tenth of the compressive strength. In fact, the strength parameters used will be smaller when they are substituted into the conversion formula in MatDEM, so the strength parameters taken here will look much larger [50]. Other parameters were consistent with Table 1.

Figure 12 shows the scraping depth and the thickness of the deposit under different strengths. Comparative analysis shows that the smaller the strength, the greater the depth and area of the scraping. Since the scrapped volume increases greatly, the thickness of the deposits will also become greater.

Figures 13 and 14 show the average displacement and velocity of the source area and the scraping area elements under different strengths. Comparative analysis shows that the smaller the strength, the greater the average displacement and velocity of the elements.

Figure 15 shows the total heat generated by landslide movement under different strengths. It can be seen from the figure that, as the strength decreases, the total heat generated will gradually increase.

It can be drawn from formulas A3 and A4 of Appendix that, under the same conditions of other parameters, when $T_{\mathrm{u}}$ and $C_{\mathrm{u}}$ decrease, the fracture displacement $X_{\mathrm{b}}$ and the initial shear force $F s_{0}$ between the elements also decrease. At this time, the connection between two elements is easily broken. Therefore, with the increase in the volume of the scraping elements and the thickness of the deposits, the scraping effect increases. The sliding distance will also become longer due to the scale effect of the high-speed and long-runout landslide. Meanwhile, more and more gravitational potential energy is converted into heat, so the total heat generated gradually increases.

4.5.2. Influence of the Internal Friction Coefficient Change on the Landslide Movement Process. Since rainfall has a lubricating effect on the sliding surface and causes the internal friction coefficient to decrease, we use different internal friction coefficients to simulate the influence of the decrease in the friction. Four sets of control experiments were carried out. The internal friction coefficient $\mu_{i}$ was set to $0.43,0.45$, 0.47 , and 0.49 , respectively, and the other parameters were consistent with Table 1.

Figure 16 shows the scraping depth and the deposits' thickness of the landslide under different internal friction coefficients. Comparative analysis shows that the smaller the internal friction coefficient, the greater the depth and area of scraping. The scrapped volume increases greatly, so the thickness of the deposits will also become greater. When the internal friction coefficient is too large $\left(\mu_{i}=0.49\right)$, there is no scraping, and the elements are mostly accumulated on the scraping area.

Figures 17 and 18 show the average displacement and velocity of the source area and the scraping area elements 


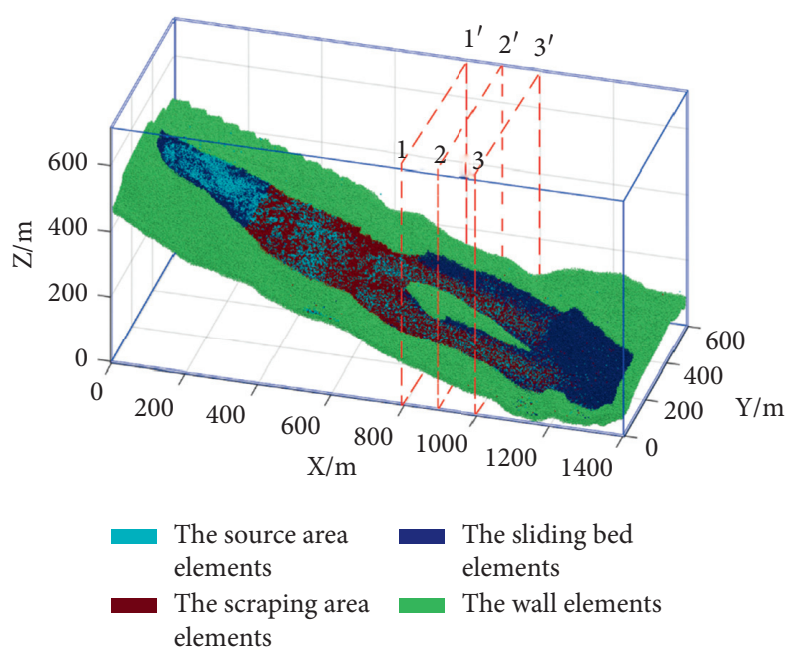

(a)

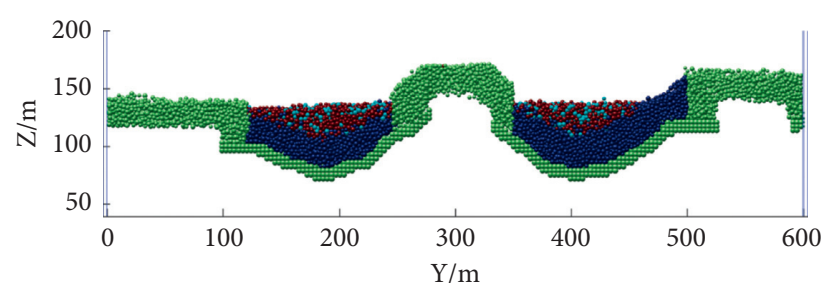

(b)

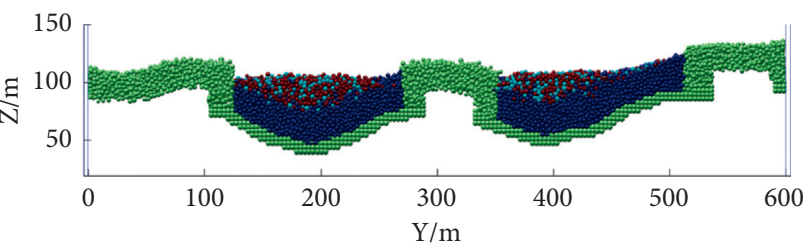

(c)

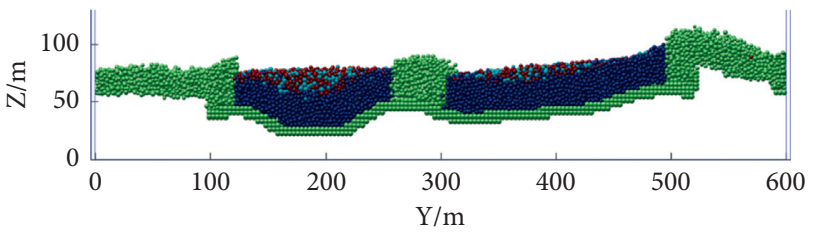

(d)

FIGURE 11: Final distribution and section of the landslide elements. (a) Distribution of all the elements; (b) $1-1^{\prime}$ section; (c) $2-2^{\prime}$ section; (d) 3-3' section.

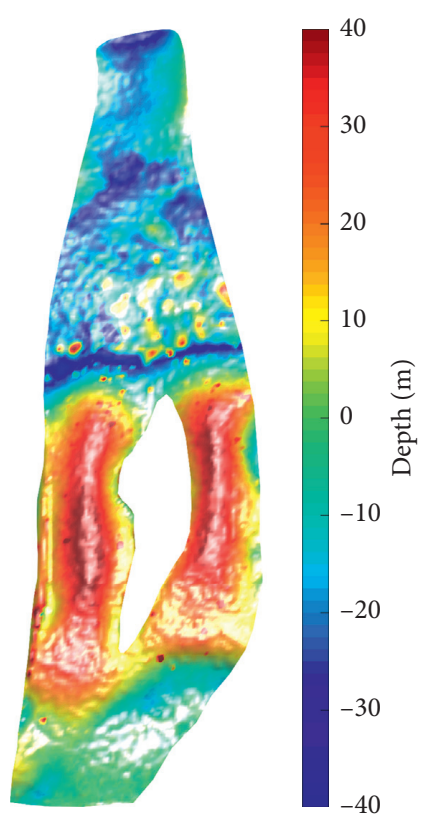

(a)



(b)

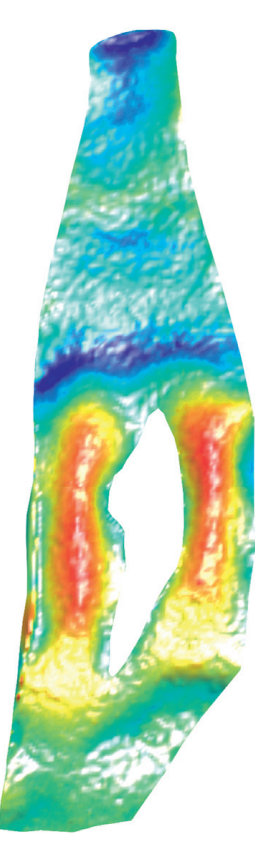

(c)
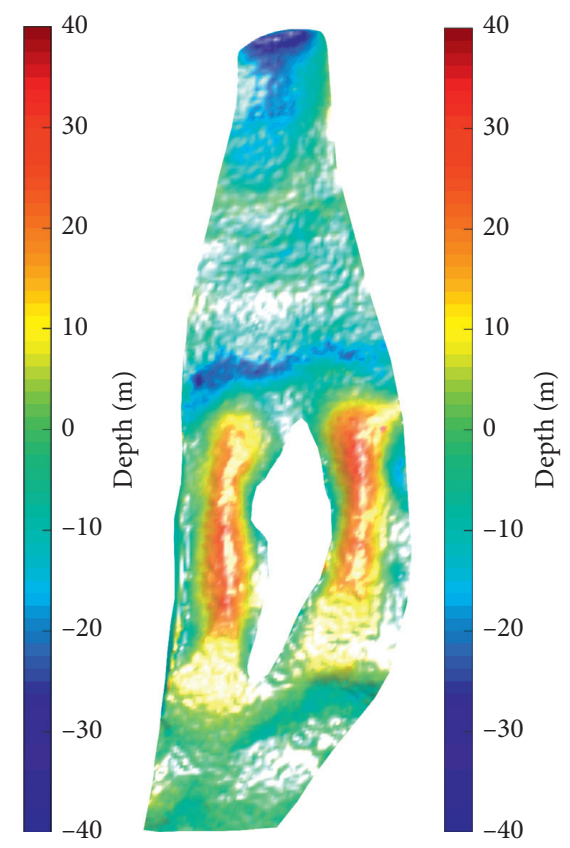

(d)

FIGURE 12: Distribution of scraping depth and deposit thickness of four materials with different strengths. (a) Material 1, (b) Material 2, (c) Material 3, and (d) Material 4.

under different internal friction coefficients. Comparative analysis shows that when the internal friction coefficient becomes smaller, the average displacement and velocity of the elements will become larger.
Figure 19 shows the total heat generated by the landslide movement at different internal friction coefficients. It can be seen from the figure that, as the internal friction coefficient decreases, the total heat generated will gradually increase. 


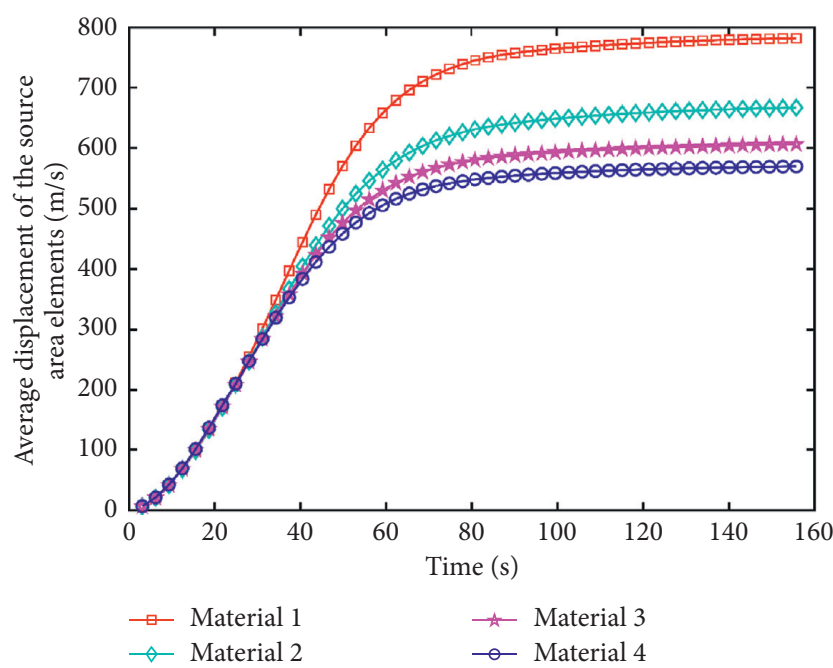

(a)

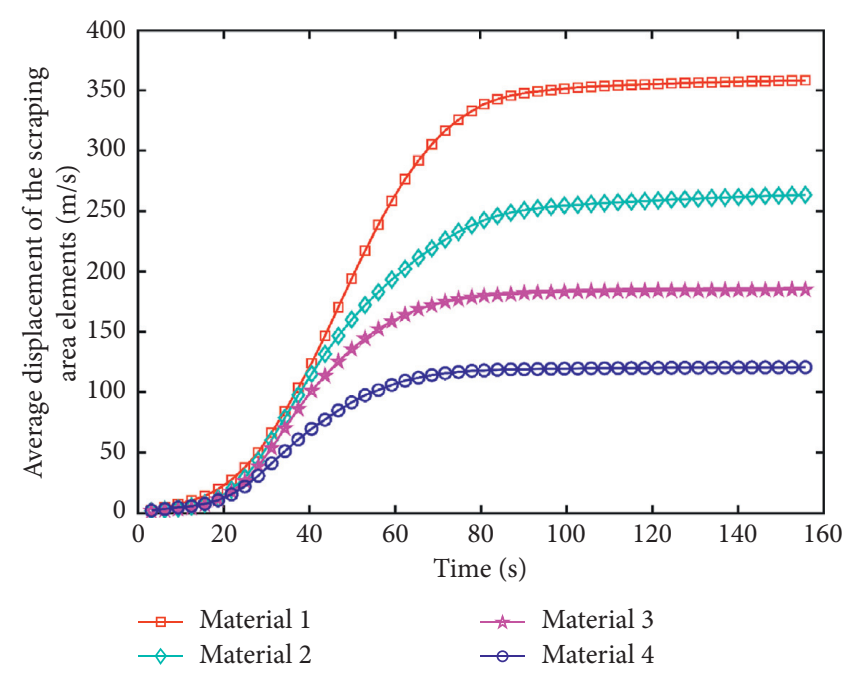

(b)

FIGURE 13: The average displacement of the (a) source area and (b) scraping area elements of four materials with different strength.

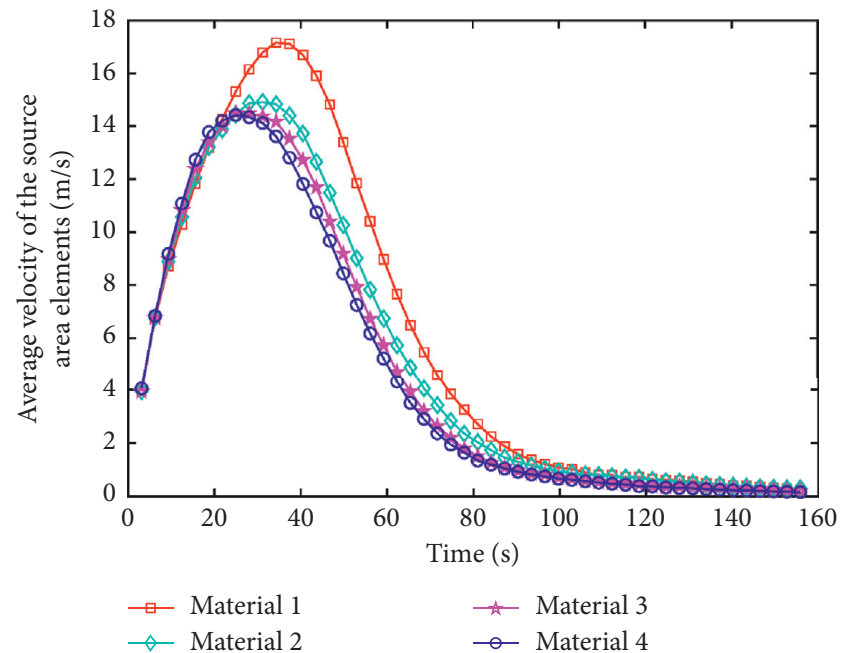

(a)

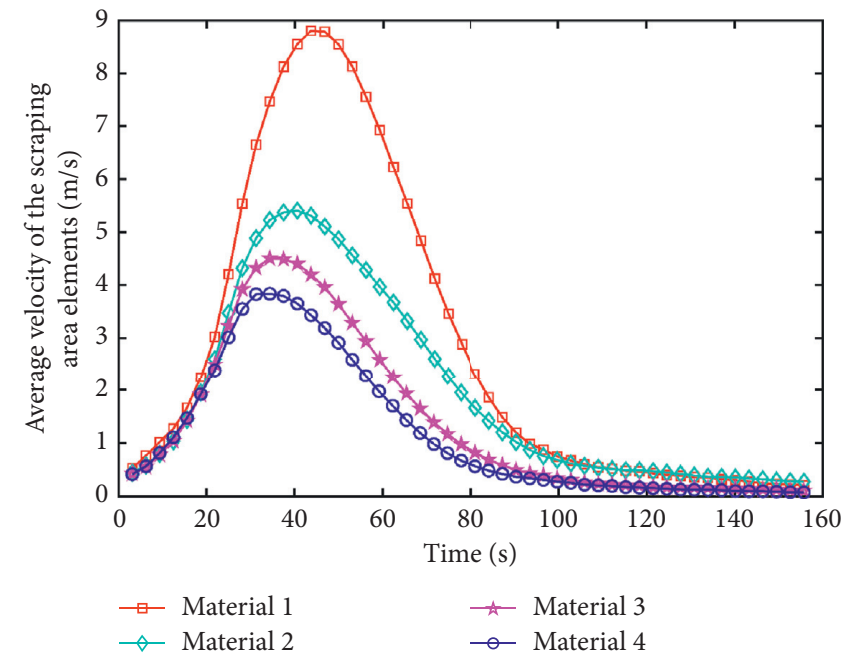

(b)

Figure 14: The average velocity of the (a) source area and (b) scraping area elements of four materials with different strength.

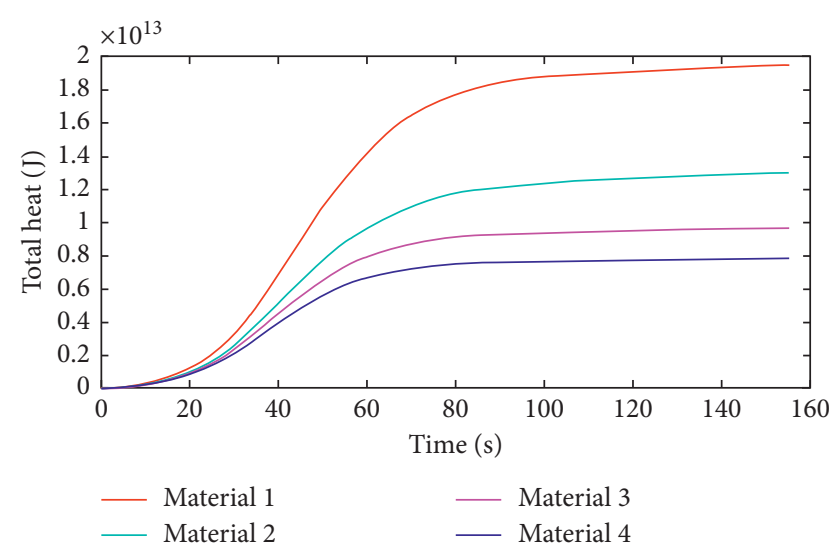

FIGURE 15: Total heat change curve of four materials with different strengths.
Since the internal friction coefficient is smaller, the elements are easier to slide, so the number of active elements in the scraping area will increase, which leads to the increase of the average speed and displacement of the elements as well as the depth and accumulation thickness of the scraping. It can be drawn from Figure 10 that the total heat is mainly generated by the frictional heat. When the internal friction coefficient decreases, the scraping effect between the elements will increase, and the friction between the elements will also increase which causes the friction heat to become larger.

\section{Discussion}

When the source area elements passed through the scraping area, the elements' velocity and friction heat increase rapidly 


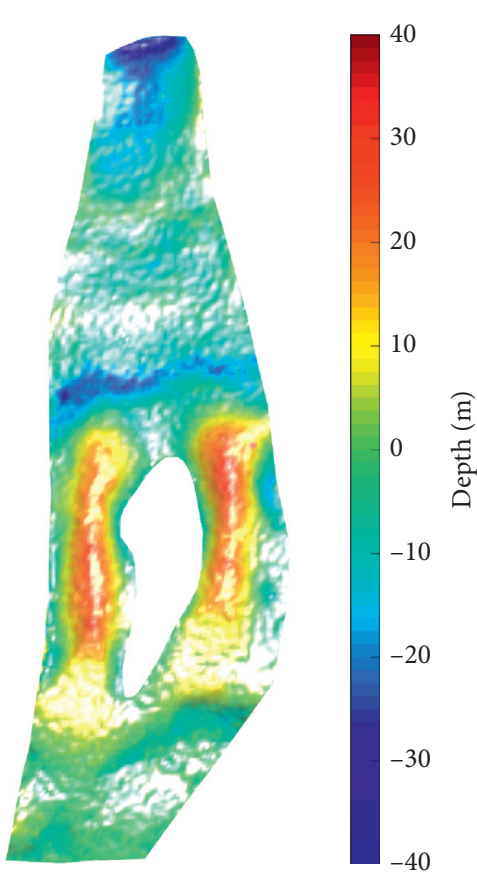

(a)

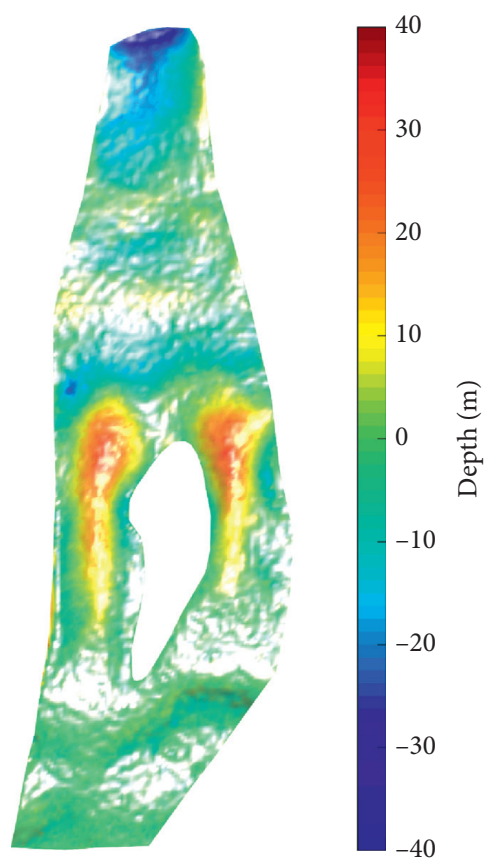

(c)

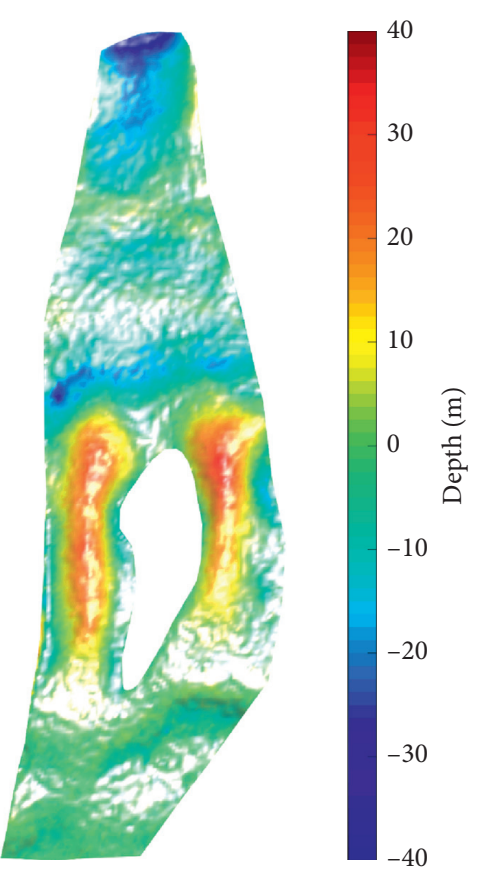

(b)

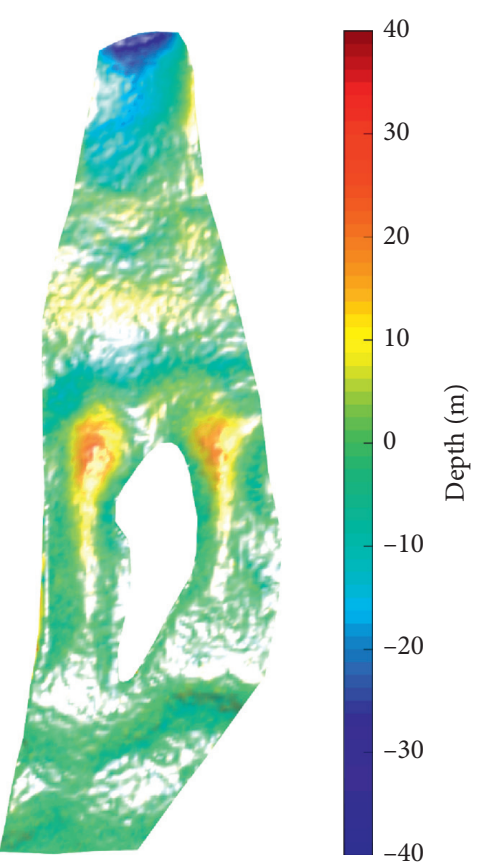

(d)

Figure 16: Distribution of scraping depth and deposit thickness under different internal friction coefficients. (a) $\mu_{i}=0.43$. (b) $\mu_{i}=0.45$. (c) $\mu_{i}=0.47$. (d) $\mu_{i}=0.49$.

(Figures 9 and 10). The friction heat change has a certain positive correlation with the velocity of elements in the scraping area. Related references show that the high temperature generated by frictional heat will weaken the friction effect and cause the elements' velocity to increase rapidly [52-55].

Considering the genetic mechanism of high-speed and long-runout landslides, some researchers have successively proposed the fluidized-bed hypothesis [56], the air-layer lubrication hypothesis [57], grainflow hypothesis [1], and various hypotheses considering the effect of pore water $[58,59]$. The final conclusions of these theories are to reduce the strength of the rock and soil or the frictional resistance of the sliding surface, which ultimately leads to the occurrence of high-speed and long-runout landslides. This paper analyzes the influence of several different strengths and internal 


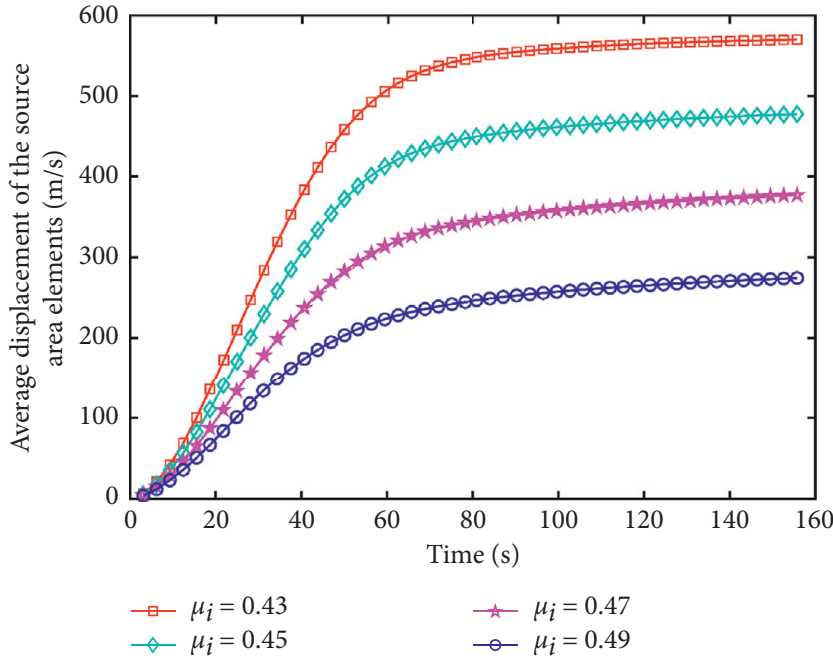

(a)

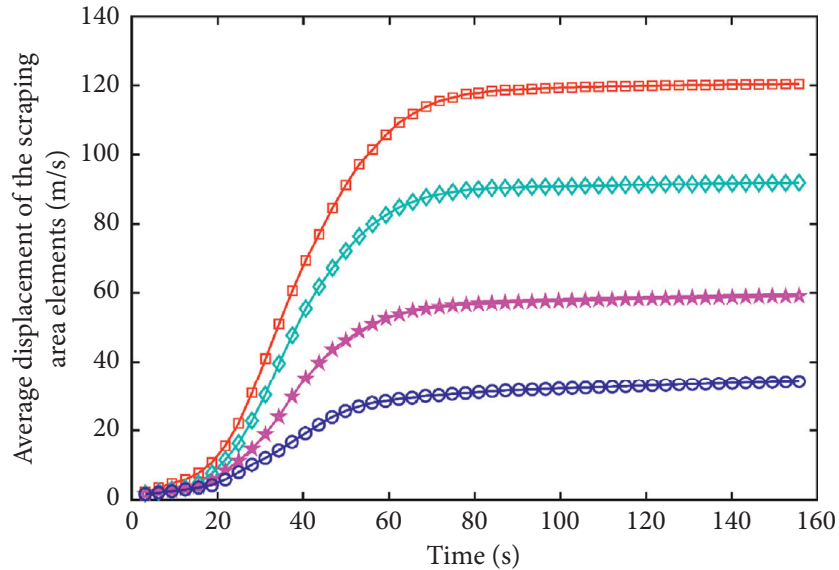

$\begin{array}{ll}\rightarrow-\mu_{i}=0.43 & \rightarrow \mu_{i}=0.47 \\ \neg \mu_{i}=0.45 & \rightarrow \mu_{i}=0.49\end{array}$

(b)

FIGURE 17: The average displacement of the (a) source area and (b) scraping area elements under different internal friction coefficients.

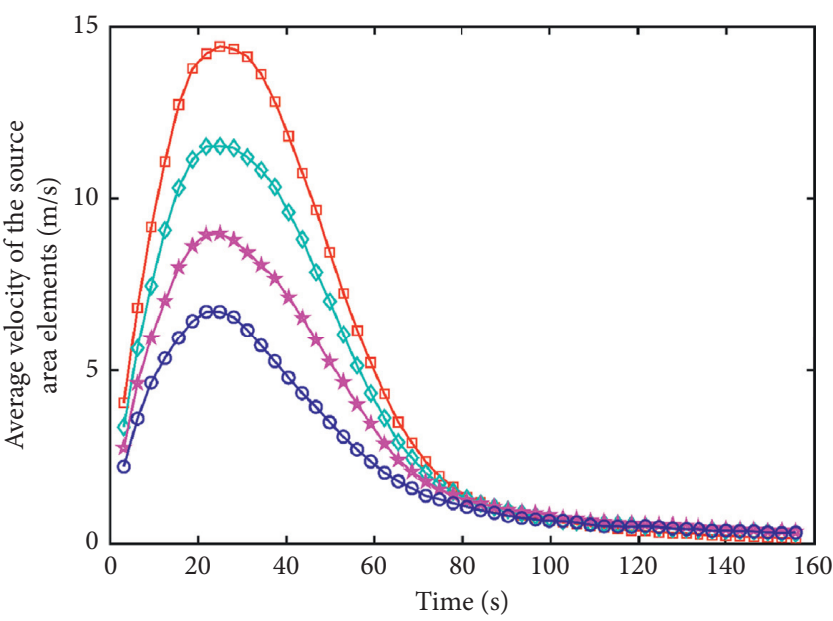

$$
\begin{array}{ll}
\rightarrow \mu_{i}=0.43 & \text { औ } \mu_{i}=0.47 \\
\neg-\mu_{i}=0.45 & \multimap-\mu_{i}=0.49
\end{array}
$$

(a)

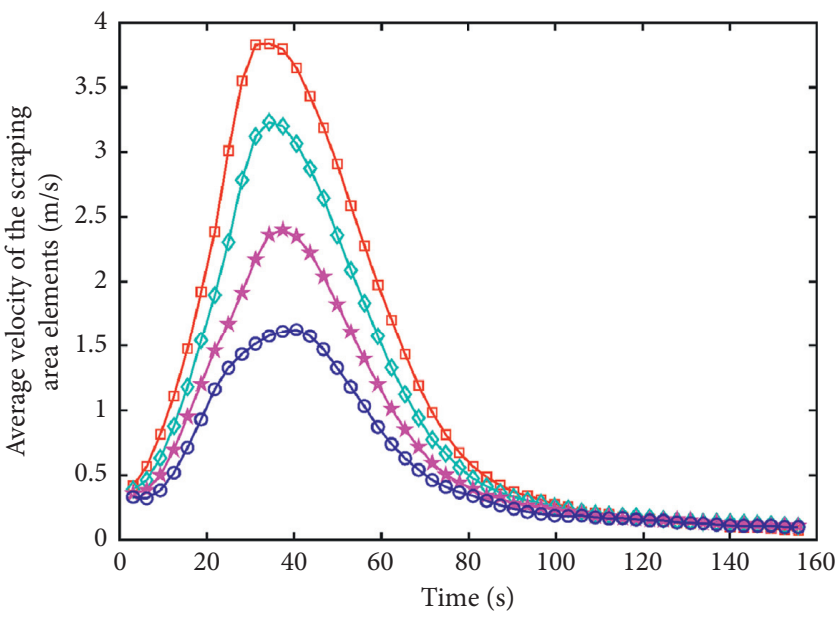

$$
\begin{array}{ll}
\rightarrow \mu_{i}=0.43 & \text { औ } \mu_{i}=0.47 \\
\neg-\mu_{i}=0.45 & \rightarrow-\mu_{i}=0.49
\end{array}
$$

(b)

FIGURE 18: The average velocity of the (a) source area and (b) scraping area elements under different internal friction coefficients.

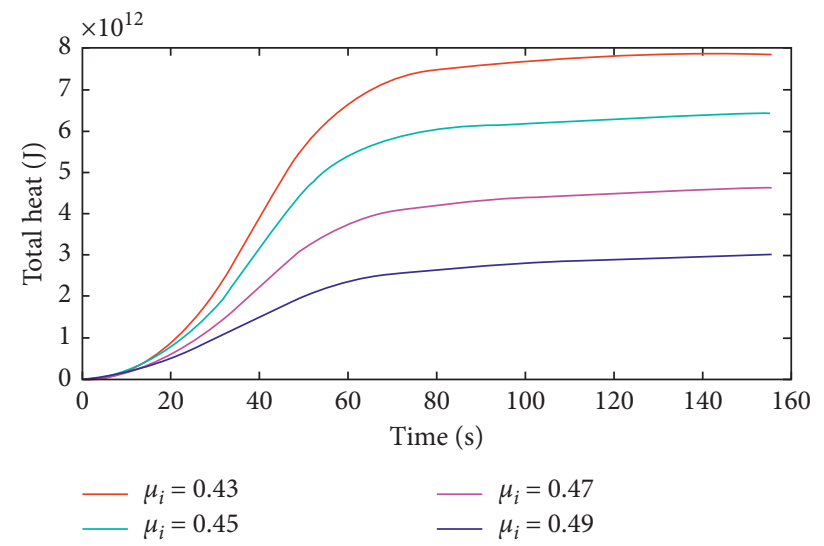

Figure 19: Total heat change curve under different internal friction coefficients. 
friction coefficients on the landslide movement. The results show that when the strengths and internal friction coefficient decrease, the scraping effect will increase, and the average displacement and velocity of the elements as well as the total heat will increase, which is consistent with the conclusions drawn in the existing references. In addition, the scraping effect will increase the volume of the sliding body. According to the scale effect of the high-speed and long-runout landslide, this will increase the area of the disaster. The scraping area elements in the deposition area account for a large proportion (Figure 11), which also proves that at this point.

Rebuilding the movement process of landslides is conducive to our understanding of its cause and movement mechanism, and it plays an important role in the early identification and warning of landslides. Analyzing the parameters that affect the landslide movement is conducive to the assessment of the impact area of landslide disasters so that we can better prevent them and minimize the casualties and property losses caused by landslides.

\section{Conclusions}

This paper used the discrete element software MatDEM to establish the Shuicheng landslide model based on the digital elevation data of the landslide obtained by UAV and simulated the initiation, high-speed sliding, and accumulation process of the landslide. The displacement, velocity, and heat generation during the movement of the landslide were analyzed, as well as the distribution characteristics of deposits. Finally, by setting different compressive and tensile strengths as well as friction coefficients, we also analyzed the influence of their value changes on the landslide movement process. The following conclusions were obtained:

(1) When the source area elements passed through the scraping area, it interacted with the scraping area elements, the speed of which increased rapidly. The average speed of the source area elements reached the maximum value of $14 \mathrm{~m} / \mathrm{s}$. Compared with the source area elements, the scraping area elements had a hysteresis when it reached the maximum speed. At $90 \mathrm{~s}$, the displacement of the source area elements reached the maximum value of $1358.5 \mathrm{~m}$. The curves of the average displacement and velocity of all active elements gradually appear to be flat until $121 \mathrm{~s}$.

(2) The total heat generated by the landslide movement process is mainly composed of the friction heat, and the change trend of them is basically the same. When the source area elements passed through the scraping area, the friction heat increased rapidly, and the breaking heat gradually rose. At this time, the change of friction heat has a certain positive correlation with the velocity of the scraping area elements.

(3) In the final deposition, the elements from the source area and the scraping area are mixed, and the volume of the scraping area elements is 2.4 times of the source area elements. The scraping effect caused the scraping area elements to slide and increased the volume of the sliding body which expanded the impact area of landslide disasters.

(4) The smaller the strength and internal friction coefficient of the model, the greater the depth and area of the scraping, and the thickness of the deposits will increase accordingly, as well as the average displacement, average velocity, and heat.

\section{Appendix}

\section{Macro- and Micromechanical Properties' Conversion Formulas of the Discrete Element Model}

There is an analytical solution between the macro and micromechanical parameters of the tightly packed discrete element model, that is, the conversion formula proposed by Liu et al. For the linear elastic model, there are five micromechanical parameters, that is, the normal stiffness $\left(K_{\mathrm{n}}\right)$, shear stiffness $\left(K_{\mathrm{s}}\right)$, breaking displacement $\left(X_{\mathrm{b}}\right)$, initial shear force $\left(F_{\mathrm{s} 0}\right)$, and interparticle friction coefficient $\left(\mu_{p}\right)$. These micromechanical parameters can be determined by the five macromechanical parameters, i.e., Young's modulus $(E)$, Poisson's ratio $(v)$, compressive strength $\left(C_{\mathrm{u}}\right)$, tensile strength $\left(T_{\mathrm{u}}\right)$, and internal friction coefficient $\left(\mu_{i}\right)$. The conversion formulas are as follows:

$$
\begin{aligned}
K_{n} & =\frac{\sqrt{2} E d}{4(1-2 v)}, \\
K_{s} & =\frac{\sqrt{2}(1-5 v) E d}{4(1+v)(1-v)}, \\
X_{b} & =\frac{3 K_{n}+K_{s}}{6 \sqrt{2} K_{n}\left(K_{n}+K_{s}\right)} \cdot T_{u} \cdot d^{2}, \\
F s_{0} & =\frac{1-\sqrt{2} \mu_{p}}{6} \cdot C_{u} \cdot d^{2}, \\
\mu_{p} & =\frac{-2 \sqrt{2}+\sqrt{2} I}{2+2 I}, \\
I & =\left[\left(1+\mu_{i}^{2}\right)^{(1 / 2)}+\mu_{i}\right]^{2} .
\end{aligned}
$$

\section{Data Availability}

The source code and related data of the numerical simulation used to support the findings of this study can be downloaded from the website (http://matdem.com).

\section{Conflicts of Interest}

The authors declare that there are no conflicts of interest regarding the publication of this paper. 


\section{Acknowledgments}

This work was supported and funded by the National Natural Science Foundation of China (Grant nos. 41761134089 and 41977218) and Six Talent Peaks Project of Jiangsu Province (Grant no. RJFW-003).

\section{References}

[1] K. J. Hsü, "Catastrophic debris streams (sturzstroms) generated by rockfalls," Geological Society of America Bulletin, vol. 86, no. 1, pp. 129-140, 1975.

[2] N. Pollet and J. L. M. Schneider, "Dynamic disintegration processes accompanying transport of the holocene Flims sturzstrom (Swiss Alps)," Earth and Planetary Science Letters, vol. 221, no. 1-4, pp. 433-448, 2004.

[3] O. Hungr, S. Leroueil, and L. Picarelli, "The Varnes classification of landslide types, an update," Landslides, vol. 11, no. 2, pp. 167-194, 2014.

[4] B. Wen, S. Wang, E. Wang, and J. Zhang, "Characteristics of rapid giant landslides in China," Landslides, vol. 1, no. 4, pp. 247-261, 2004.

[5] H. Runqiu, "Some catastrophic landslides since the twentieth century in the southwest of China," Landslides, vol. 6, no. 1, pp. 69-81, 2009.

[6] A. Xing, G. Wang, Y. Yin, C. Tang, Z. Xu, and W. Li, "Investigation and dynamic analysis of a catastrophic rock avalanche on September 23, 1991, Zhaotong, China," Landslides, vol. 13, no. 5, pp. 1035-1047, 2016.

[7] Q. Xu, Y. Shang, T. Van Asch, S. Wang, Z. Zhang, and $\mathrm{X}$. Dong, "Observations from the large, rapid Yigong rock slide - debris avalanche, southeast Tibet," Canadian Geotechnical Journal, vol. 49, no. 5, pp. 589-606, 2012.

[8] G. Wang, R. Huang, S. D. N. Lourenço, and T. Kamai, "A large landslide triggered by the 2008 Wenchuan (M8.0) earthquake in Donghekou area: phenomena and mechanisms," Engineering Geology, vol. 182, pp. 148-157, 2014.

[9] Y. Yin, P. Sun, M. Zhang, and B. Li, "Mechanism on apparent dip sliding of oblique inclined bedding rockslide at Jiweishan, Chongqing, China," Landslides, vol. 8, no. 1, pp. 49-65, 2011.

[10] Y. Yin, P. Sun, J. Zhu, and S. Yang, "Research on catastrophic rock avalanche at Guanling, Guizhou, China," Landslides, vol. 8, no. 4, pp. 517-525, 2011.

[11] X. Fan, Q. Xu, G. Scaringi et al., "Failure mechanism and kinematics of the deadly june 24th 2017 Xinmo landslide, maoxian, sichuan, China," Landslides, vol. 14, no. 6, pp. 2129-2146, 2017.

[12] Y. Okura, H. Kitahara, T. Sammori, and A. Kawanami, "The effects of rockfall volume on runout distance," Engineering Geology, vol. 58, no. 2, pp. 109-124, 2000.

[13] F. Legros, "The mobility of long-runout landslides," Engineering Geology, vol. 63, no. 3-4, pp. 301-331, 2002.

[14] I. Manzella and V. Labiouse, "Flow experiments with gravel and blocks at small scale to investigate parameters and mechanisms involved in rock avalanches," Engineering $\mathrm{Ge}$ ology, vol. 109, no. 1-2, pp. 146-158, 2009.

[15] F. V. De Blasio, H. Breien, and A. Elverhøi, "Modelling a cohesive-frictional debris flow: an experimental, theoretical, and field-based study," Earth Surface Processes and Landforms, vol. 36, no. 6, pp. 753-766, 2011.

[16] W.-J. Xu, Q. Xu, and Y.-J. Wang, "The mechanism of highspeed motion and damming of the Tangjiashan landslide," Engineering Geology, vol. 157, pp. 8-20, 2013.
[17] W. Shen, T. Li, P. Li, and J. Guo, "A modified finite difference model for the modeling of flowslides," Landslides, vol. 15, no. 8, pp. 1577-1593, 2018.

[18] L. Wang, S. Wang, G. Li et al., "Construction of 3D creep model of landslide slip-surface soil and secondary development based on FLAC3D," Advances in Civil Engineering, vol. 2020, Article ID 2694651, 15 pages, 2020.

[19] L. Li, M. Zhai, X. Ling et al., "On the location of multiple failure slip surfaces in slope stability problems using the meshless SPH algorithm," Advances in Civil Engineering, vol. 2020, Article ID 6821548, 8 pages, 2020.

[20] Y. Song, D. Huang, and D. Cen, "Numerical modelling of the 2008 Wenchuan earthquake-triggered Daguangbao landslide using a velocity and displacement dependent friction law," Engineering Geology, vol. 215, pp. 50-68, 2016.

[21] M. Jiang, T. Jiang, G. B. Crosta, Z. Shi, H. Chen, and N. Zhang, "Modeling failure of jointed rock slope with two main joint sets using a novel DEM bond contact model," Engineering Geology, vol. 193, pp. 79-96, 2015.

[22] T. Zhao, G. B. Crosta, S. Utili, and F. V. De Blasio, "Investigation of rock fragmentation during rockfalls and rock avalanches via $3-\mathrm{D}$ discrete element analyses," Journal of Geophysical Research: Earth Surface, vol. 122, no. 3, pp. 678-695, 2017.

[23] J.-W. Zhou, P. Cui, and X.-G. Yang, "Dynamic process analysis for the initiation and movement of the Donghekou landslide-debris flow triggered by the Wenchuan earthquake," Journal of Asian Earth Sciences, vol. 76, pp. 70-84, 2013.

[24] L. Cascini, S. Cuomo, M. Pastor, and I. Rendina, "SPH-FDM propagation and pore water pressure modelling for debris flows in flume tests," Engineering Geology, vol. 213, pp. 74-83, 2016.

[25] O. Hungr and S. G. Evans, "Entrainment of debris in rock avalanches: an analysis of a long run-out mechanism," Geological Society of America Bulletin, vol. 116, no. 9-10, pp. 1240-1252, 2004.

[26] B. Sovilla, P. Burlando, and P. Bartelt, "Field experiments and numerical modeling of mass entrainment in snow avalanches," Journal of Geophysical Research: Earth Surface, vol. 111, no. F3, 2006.

[27] G. B. Crosta, S. Imposimato, and D. Roddeman, "Numerical modelling of entrainment/deposition in rock and debris-avalanches," Engineering Geology, vol. 109, no. 1-2, pp. 135-145, 2009.

[28] W. Shen, T. Li, P. Li, Y. Shen, Y. Lei, and J. Guo, "The influence of the bed entrainment-induced rheology and topography changes on the propagation of flow-like landslides: a numerical investigation," Bulletin of Engineering Geology and the Environment, vol. 78, no. 7, pp. 4771-4785, 2019.

[29] R. M. Iverson, "Elementary theory of bed-sediment entrainment by debris flows and avalanches," Journal of Geophysical Research: Earth Surface, vol. 117, no. F3, 2012.

[30] S. Cuomo, M. Pastor, L. Cascini, and G. C. Castorino, "Interplay of rheology and entrainment in debris avalanches: a numerical study," Canadian Geotechnical Journal, vol. 51, no. 11, pp. 1318-1330, 2014.

[31] C. Ouyang, K. Zhou, Q. Xu et al., "Dynamic analysis and numerical modeling of the 2015 catastrophic landslide of the construction waste landfill at Guangming, Shenzhen, China," Landslides, vol. 14, no. 2, pp. 705-718, 2016.

[32] J. Mao, X. Liu, C. Zhang et al., Runout Prediction and Deposit Characteristics Investigation by the Distance Potential-Based Discrete Element Method: The 2018 Baige Landslides, Landslides, Jinsha River, China, 2020. 
[33] L. Zhang, H. M. Tang, C. Z. Xiong et al., "Movement process simulation of high-speed long-distance Jiweishan landslide with PFC ${ }^{3 \mathrm{D}}$," Chinese Journal of Rock Mechanics and Engineering, vol. 31, no. S1, pp. 2601-2611, 2012, In Chinese.

[34] C. Liu, T. C. Le, B. Shi et al., "Discussion on the three major problems of the engineering application of the particle discrete element method," Chinese Journal of Rock Mechanics and Engineering, vol. 39, no. 6, pp. 1142-1152, 2020, In Chinese.

[35] S. Ma, C. Xu, X. Xu et al., "Characteristics and causes of the landslide on july 23, 2019 in Shuicheng, Guizhou province, China. landslides," Landslide, vol. 17, pp. 1441-1452, 2020.

[36] F. Si, H. Yin, F. Li, B. Zhang, and M. Li, "Characteristics and causes of geological hazards and the preventive measures in Shuicheng, Guizhou, China," The Chinese Journal of Geological Hazard and Control, vol. 23, pp. 112-115, 2012, in Chinese.

[37] X. Cao, Q. Zhou, and C. Liu, "Distribution pattern of coseismic landslides triggered by the 2014 ludian, Yunnan, China Mw6.1 earthquake: special controlling conditions of local topography," Landslides, vol. 12, no. 6, pp. 1159-1168, 2015.

[38] J. Guo, S. Yi, Y. Yin et al., "The effect of topography on landslide kinematics: a case study of the Jichang town landslide in Guizhou, China," Landslides, vol. 17, pp. 959-973, 2020.

[39] X. Fan, J. Tang, S. Tian et al., "Rainfall-induced rapid and long-runout catastrophic landslide on July 23, 2019 in Shuicheng, Guizhou, China," Landslides, vol. 17, pp. 21612171, 2020.

[40] C. Cao, Z. Xu, J. Chai, and Y. Li, "Radial fluid flow regime in a single fracture under high hydraulic pressure during shear process," Journal of Hydrology, vol. 579, Article ID 124142, 2019.

[41] A. Rahimi, H. Rahardjo, and E.-C. Leong, "Effect of antecedent rainfall patterns on rainfall-induced slope failure," Journal of Geotechnical and Geoenvironmental Engineering, vol. 137, no. 5, pp. 483-491, 2011.

[42] J. Peng, Z. Fan, D. Wu et al., "Heavy rainfall triggered loessmudstone landslide and subsequent debris flow in Tianshui, China," Engineering Geology, vol. 186, pp. 79-90, 2015.

[43] Z. Lyu, J. Chai, Z. Xu, Y. Qin, and J. Cao, "A comprehensive review on reasons for tailings dam failures based on case history," Advances in Civil Engineering, vol. 2019, no. 9, 18 pages, Article ID 4159306, 2019.

[44] S. Wang, K. Zhang, L. P. H. V. Beek et al., "Physically-based landslide prediction over a large region: scaling low-resolution hydrological model results for high-resolution slope stability assessment," Environmental Modelling \& Software, vol. 124, Article ID 104607, 2019.

[45] W. Hu, Q. Xu, G. Wang et al., "Shear resistance variations in experimentally sheared mudstone granules: a possible shearthinning and thixotropic mechanism," Geophysical Research Letters, vol. 44, 2017.

[46] G. Scaringi, X. Fan, Q. Xu et al., "Some considerations on the use of numerical methods to simulate past landslides and possible new failures: the case of the recent Xinmo landslide (Sichuan, China)," Landslides, vol. 15, no. 7, pp. 1359-1375, 2018.

[47] C. Liu, X. M. Fan, C. G. Zhu et al., "Discrete element modeling and simulation of 3-Dimensional large-scale landslide-C-taking Xinmocun landslide as an example," Journal of Engineering Geology, vol. 27, no. 6, pp. 1362-1370, 2019, in Chinese.
[48] P. A. Cundall and O. D. L. Strack, "A discrete numerical model for granular assemblies," Géotechnique, vol. 30, no. 30, pp. 331-336, 1979.

[49] C. Zuo, Q. Chen, G. Gu et al., "High-speed three-dimensional shape measurement for dynamic scenes using bi-frequency tripolar pulse-width-modulation fringe projection," Optics and Lasers in Engineering, vol. 51, no. 8, pp. 953-960, 2013.

[50] C. Liu, Q. Xu, B. Shi, S. Deng, and H. Zhuet al., "Mechanical properties and energy conversion of 3D close-packed lattice model for brittle rocks," Computers \& Geosciences, vol. 103, no. C, pp. 12-20, 2017.

[51] Y. Gao, B. Li, H. Gao et al., "Dynamic characteristics of highelevation and long-runout landslides in the Emeishan basalt area: a case study of the Shuicheng " 7.23 " landslide in Guizhou, China," Landslides, vol. 17, pp. 1-15, 2020.

[52] A. Lucas, A. Mangeney, and J. P. Ampuero, "Frictional velocity-weakening in landslides on Earth and on other planetary bodies," Nature Communications, vol. 5, no. 1, pp. 1-9, 2014.

[53] Y. F. Wang, J. J. Dong, and Q. G. Cheng, "Velocity-dependent frictional weakening of large rock avalanche basal facies: implications for rock avalanche hypermobility?" Journal of Geophysical Research: Solid Earth, vol. 122, no. 3, pp. 16481676, 2017.

[54] W. Hu, R. Huang, M. McSaveney et al., "Superheated steam, hot $\mathrm{CO} 2$ and dynamic recrystallization from frictional heat jointly lubricated a giant landslide: field and experimental evidence," Earth and Planetary Science Letters, vol. 510, pp. 85-93, 2019.

[55] Y. Deng, S. Yan, G. Scaringi et al., “An empirical power density-based friction law and its implications for coherent landslide mobility," Geophysical Research Letters, vol. 47, Article ID e2020GL087581, 2020.

[56] P. E. Kent, "The transport mechanism in catastrophic rock falls," The Journal of Geology, vol. 74, no. 1, pp. 79-83, 1966.

[57] R. L. Shreve, "Sherman landslide, Alaska," Science, vol. 154, no. 3757, pp. 1639-1643, 1966.

[58] S. G. Evans, O. Hungr, and J. J. Clague, "Dynamics of the 1984 rock avalanche and associated distal debris flow on Mount Cayley, British Columbia, Canada; implications for landslide hazard assessment on dissected volcanoes," Engineering Geology, vol. 61, no. 1, pp. 29-51, 2001.

[59] S. P. Pudasaini, "A general two-phase debris flow model," Journal of Geophysical Research: Earth Surface, vol. 117, no. F3, 2012. 